\title{
Prognostic Effect of Glycemic Management In Acute First-Ever Ischemic Stroke On Stroke Recurrence And Mortality For Patients Without Previous Diabetes: A Longitudinal Cohort Study
}

\author{
Hsi- Hsing Yang \\ Chi Mei Medical Center \\ Wu-Chien Chien \\ National Defense Medical Center \\ Jen-Jiuan Liaw \\ National Defense Medical Center \\ Chia-Chen Yang \\ National Defense Medical Center \\ Chi-Hsiang Chung \\ National Defense Medical Center \\ Peng-Ciao Chen \\ National Defense Medical Center \\ Ting-Ti Lin \\ National Defense Medical Center \\ Yu-Ju Chen ( $\boldsymbol{\sigma}$ judychen37@gmail.com ) \\ National Defense Medical Center
}

\section{Research Article}

Keywords: glycemic, stroke, hyperglycemia, FISHGw/GT, treatment

Posted Date: September 17th, 2021

DOI: https://doi.org/10.21203/rs.3.rs-877768/v1

License: (c) (i) This work is licensed under a Creative Commons Attribution 4.0 International License. Read Full License 


\section{Abstract}

Objective This study aimed to investigate the short- and long-term prognostic effects of glycemic management on stroke recurrence and mortality in patients with acute first-ever ischemic stroke (FIS) without previous diabetes.

Methods In total, 484,952 patients aged $\geq 20$ years with FIS and nonprevious diabetes were retrieved from the 2000 to 2015 Taiwan's National Health Insurance Research Database. Patients were categorized into the following cohorts: FIS without hyperglycemia (FISw/oHG), FIS with hyperglycemia without glycemic treatment (FISHGw/oGT), and FIS with hyperglycemia with glycemic treatment (FISHGw/GT). The short-term (within 1 year) and long-term (at the endpoint of $9.3 \pm 8.6$ years) prognostic effects of glycemic treatment and blood glucose monitoring on stroke recurrence and mortality among the cohorts were tested through Cox regression analysis.

Results The mortality risk was lower in the FISHGw/GT cohort than in the FISHGw/oGT cohort at 3 months, 6 months, and 1 year (adjusted hazard ratio $=0.68,0.62,0.69$, respectively, $p<0.001$ ) as well as at the study endpoint, but no difference was observed in stroke recurrence at any time point $(p>0.05)$. Furthermore, compared with FISHGw/oGT without blood glucose monitoring, FISHGw/GT combined with blood glucose monitoring led to decreased risks of stroke recurrence within 1 year $(p<0.001)$ and mortality within 1 year and at the study endpoint $(p<0.001)$.

Conclusion For optimal glycemic management in the acute phase and improved prognoses for patients with FIS and nonprevious diabetes with hyperglycemia, intensive blood glucose monitoring combined with glycemic treatment is needed.

\section{Introduction}

Ischemic stroke, also known as central nervous system infarction, leads to the disruption of blood supply to the brain, which can cause brain cell death and brain damage ${ }^{1}$. As a result, patients with acute ischemic stroke (AIS) experience a sudden unexpected decline in cognition, autonomic nervous system function, and executive functions, leading to focal neurological deficit ${ }^{1,2}$. In addition, stroke recurrence is frequent and cumulative, ranging from $5.4-10.4 \%$ at 1 year to $12.9-14.2 \%$ at 10 years after the first-ever stroke ${ }^{3,4}$. Furthermore, mortality and functional disability are highly associated with stroke recurrence ${ }^{5}$. Therefore, stroke recurrence and mortality rate are commonly regarded as indicators of the effectiveness of health care intervention in patients with AIS.

Hyperglycemia has been observed in $40-60 \%$ of patients with AIS; it is a response to the acute stress from brain damage and known as poststroke hyperglycemia ${ }^{6,7}$. It is considered an essential survival response and usually disappears spontaneously after the acute phase of ischemic stroke ${ }^{8}$. However, evidence indicates that poststroke hyperglycemia is an unfavorable occurrence associated with an increased risk of morbidity, poor prognosis, and mortality ${ }^{9-11}$. 
Within 48 hours of an AIS attack, hyperglycemia has been determined to be an independent predictor for stroke recurrence ${ }^{12}$. According to an investigation of ischemic stroke recurrence within two years after the first-ever attack in a China cohort study, diabetes mellitus (DM) is a risk factor for stroke recurrence ${ }^{13}$. A systematic review indicated that the relative risk of in-hospital or 30-day mortality was higher in patients with poststroke hyperglycemia (risk in patients with and without previously diagnosed diabetes was 1.30 and 3.07 times higher, respectively) than in those with normoglycemia ${ }^{9}$. Studies have indicated that admission hyperglycemia and hyperglycemia in combination with high glycosylated hemoglobin ( $\mathrm{HbA1c}$ ) in patients with AIS are risk factors for short-term (from 3 months to 1 year after the stroke incidence) mortality, particularly in patients without a history of diabetes ${ }^{14-17}$.

Poststroke hyperglycemia is a modifiable risk factor for brain damage ${ }^{2}$. Glucose-lowering therapies reduce brain damage ${ }^{18}$. However, tight glycemic control has no significant beneficial effect on functional outcomes or survival but might increase hypoglycemia risk ${ }^{19}$. Researchers have postulated that tight glycemic control within the normal range in acute stroke might lead to brain glycopenia, which would hamper the body's ability to meet the increased metabolic demand after acute brain damage and cause hypoglycemia and metabolic crisis ${ }^{20}$. According to the guidelines for ischemic stroke management, targeting a blood glucose level of $140-180 \mathrm{mg} / \mathrm{dL}$ and closely monitoring blood glucose are crucial for poststroke hyperglycemia management 2. However, the guidelines do not indicate the glucose level threshold that requires intervention or specific insulin treatment regimens ${ }^{2}$. Furthermore, the guidelines have not recommended a particular frequency of blood glucose monitoring ${ }^{21}$.

Glycemic management is implemented conservatively and varies across countries because of the risk of iatrogenic hypoglycemia and a lack of promising effects ${ }^{22}$. The conservatove glycemic treatment in acute stroke might increase mortality, all-cause readmissions or emergency visits, recurrent stroke, infection morbidity, and psychological distress ${ }^{15}$. In addition, hyperglycemia is frequently unmanaged has been reported, and the effect of glycemic control on AIS is controversial ${ }^{21}$. However, major investigations into the prognostic longitudinal impact of glycemic management in patients with AIS are lacking. The purpose of this study was to use Taiwan's National Health Insurance Research Database (NHIRD) to investigate the shortand long-term prognostic effects of glycemic management (combined glycemic treatment with blood glucose monitoring) on stroke recurrence and mortality in patients with acute first-ever ischemic stroke (FIS) without previous diabetes.

\section{Methods}

\section{Data Sources}

This study is a retrospective cohort study and used Taiwan's NHIRD consisting of 2 million randomized populations between 2000 and 2015. Taiwan launched the single-payer National Health Insurance in 1995; since then, the NHIRD has been maintained and covers approximately $99 \%$ of the 23.74 million residents of Taiwan. It has contracts with $97 \%$ of the hospitals and clinics in Taiwan. The NHIRD contains information on medical facility registries, medication prescriptions, and inpatient, outpatient, and emergency visit data ${ }^{23}$. In 
addition, the NHIRD has been found to have high accuracy and validity for population research in ischemic stroke ${ }^{24}$.

\section{Ethics Statement}

This study was conducted in accordance with the Declaration of Helsinki. The Research Ethics Committee of the Tri-Service General Hospital of the National Defense Medical Center (TSGHIRB No. B-110-32) approved this study. Because the NHI data set comprises de-identifed secondary data for research directions, the Research Ethics Committee issued a formal written waiver for the demand for consent.

\section{Study Participants}

The participants' data were extracted from the NHIRD based on the International Classification of Diseases, 9th Revision, Clinical Modification (ICD-9-CM) codes. Patients aged $\geq 20$ years and diagnosed with FIS (ICD-9$C M$ code 433 or 434 ) at the index date-that is, those who were not previously diagnosed with any ischemic stroke (ICD-9-CM code 433 or 434) -were enrolled. Furthermore, patients with FIS with a history of DM (ICD-9CM code 250) before the index date were excluded. The index date was the date of FIS diagnosis. One-fold propensity score matching by sex, age, and index date was used, and patients were categorized into the following three cohorts: FIS without hyperglycemia (FISw/oHG), FIS with hyperglycemia (FISHG; e.g., abnormal glucose and prediabetes [ICD-9-CM code 790.29] and the first-diagnosed DM [/CD-9-CM code 250] at the index date) without glycemic treatment (FISHGw/oGT), and FISHG with glycemic treatment (FISHGw/GT). We defined glycemic treatment as medical records showing glucose-lowering medicine codes: $A 10 A B-180$, A10AC-136, A10AD-183, A10AE-54, A10BA-977, A10BB-1590, A10BF-354, A10BG-344, and A10BX-306. In addition, we retrieved patients' records with blood glucose monitoring coded as 09005C from NHIRD.

\section{Covariates}

Covariates were demographic factors, including sex, age, insurance premium, season, geographical area (location) of residence (north, center, south, or east of Taiwan), urbanization level of the residence, and care level (Table 1). These covariates were included in the multivariable model for adjustment.

\section{Outcome Measures}

The outcome variables of stroke recurrence and mortality were followed up for short and long terms. Stroke recurrence was defined as patients' rehospitalization with the primary diagnosis of ischemic stroke (ICD-9-CM code 433 or 434) after the index date. The mortality status of patients in the NHIRD was coded as " 4 " if they died during the hospitalization or " $A$ " if they were in the acute terminal stage when discharged. All enrolled patients were followed up for a short term of 1 year after the index date and for a long term until the study endpoint, which was from the index date until death, withdrawal from the NHI program, or the end of 2015, whichever occurred first.

\section{Statistical Analysis}

Continuous data are presented as means with standard deviation, and categorical data are presented as frequencies with percentages for baseline characteristics. The chi-square test and $t$-test were used to evaluate the distributions of categorical and continuous variables between cohorts, respectively. Multivariate Cox proportional hazards regression analysis was used to determine the risks of stroke recurrence and mortality 
within 1 year after the index date and up to the endpoint across cohorts. The results are presented as aHR with a $95 \% \mathrm{Cl}$. Differences in the risks of stroke recurrence and mortality among cohorts were estimated using the Kaplan-Meier method with the log-rank test. A $p$-value of $<0.05$ was considered statistically significant for two-tailed tests. All statistical analyses were performed using SPSS version 22 (IBM Corp., Armonk, NY, USA).

\section{Results}

\section{Baseline Characteristics of the Study Population}

In total, 484,952 patients with FIS met the inclusion criteria of this study, of whom 161,839 (33.4\%) had FIS with hyperglycemia (FISHG). Among patients with FISHG, 69,018 (42.7\%) had not received glycemic treatment and $92,821(57.4 \%)$ had received glycemic treatment for acute stroke. After one-fold propensity matching, the 69,018 patients were categorized into one of the following three cohorts: FIS without hyperglycemia (FISw/oHG), FISHG without glycemic treatment (FISHGw/oGT), and FISHG with glycemic treatment (FISHGw/GT) (Fig. 1). This study included 207,054 patients with FIS aged $56.5 \pm 10.3$ years, and no significant differences were observed in age and sex distribution among the three cohorts $(p=0.78$ and 1.00 , respectively; Table 1). Blood glucose was monitored in 63,672 (92.25\%) patients in the FISHGw/GT cohort and $6213(9.00 \%)$ patients in the FISHGw/oGT cohort $(p<0.001)$.

\section{Comparison of Stroke Recurrence and Mortality Among the FISw/oHG, FISHGw/oGT, and FISHGw/GT Cohorts}

After adjustment for covariates of sex, age, monthly income, seasons, geographical area of residence (location), urbanization level of the residence, and levels of care, both FISHGw/oGT and FISHGw/GT cohorts had significantly higher stroke recurrence than the FISw/oHG cohort $(p<0.05)$ within 1 year of tracking. However, at the 3-month follow-up, the FISHGw/GT cohort did not have a significantly higher stroke recurrence than the FISw/oHG cohort ( $p=0.12$; Table 1). The FISHGw/oGT and FISHGw/GT cohorts had a substantially higher mortality rate than the FISw/oHG cohort within 1 year of tracking $(p<0.05)$. At the study endpoint ( $9.3 \pm 8.6$ years), Cox regression analysis indicated that both the FISHGw/oGT and FISHGw/GT cohorts had a higher risk of stroke recurrence and mortality than the FISw/oHG cohort (adjusted hazard ratio [aHR] $=1.35$ and 1.17, $p<0.001 ; 1.34$ and 1.11, $p<0.001$, respectively; Table 2). Kaplan-Meier analysis indicated that among the three cohorts, the FISw/oHG cohort had the lowest cumulative risks of stroke recurrence and mortality in the first year, which persisted until the end of the follow-up (log-rank test; $p<$ 0.001; Fig. 2).

\section{Short- and Long-Term Prognostic Effects of Glycemic Treatment and Blood Glucose Monitoring on Stroke Recurrence in FISHG Patients}

After adjustment for covariates, the FISHGw/GT cohort had a lower but nonsignificant aHR in stroke recurrence at 1-month, 3-month, 6-month, and 1-year follow-ups $(p>0.05)$ than FISHGw/oGT cohort. In 
addition, the FISHGw/GT cohort did not have a significantly lower stroke recurrence rate than the FISHGw/oGT cohort at the study endpoint (95\% confidence interval $[\mathrm{Cl}]=0.92-1.01, p=0.79$ ).

Blood glucose monitoring in the FISHGw/GT cohort in the acute stroke phase led to a lower risk of stroke reoccurrence than that in the FISHGw/oGT cohort without blood glucose monitoring at 1-month, 3-month, 6month, and 1-year follow-ups (aHR $=0.75,0.84,0.80,0.82$, respectively; $p<0.001)$. However, FISHGw/GT combined with blood glucose monitoring in the acute stroke phase had a lower but nonsignificant risk of stroke recurrence than did FISHGw/oGT without blood glucose monitoring at the study endpoint $(p>0.05$; Table 3).

\section{Short- and Long-Term Prognostic Effect of Glycemic Treatment and Blood Glucose Monitoring on Mortality in FISHG Patients}

After adjustment for covariates, the FISHGw/GT cohort had a significantly lower risk of mortality than the FISHGw/oGT cohort at 3-month, 6-month, and 1-year follow-ups (aHR $=0.68,0.62,0.69, p<0.001$, respectively; Table 2) but not at 1-month follow-up (95\% Cl = 0.58-1.25, $p=0.45)$. The FISHGw/GT cohort had a significantly lower risk of mortality than the FISHGw/oGT cohort at the study endpoint (aHR $=0.83$, $95 \% \mathrm{Cl}=0.81-0.85, p<0.001)$.

Patients with FISHGw/GT with blood glucose monitoring in the acute stroke phase had a significantly lower risk of mortality at 1-month, 3-month, 6-month, and 1-year follow-ups than did patients with FISHGw/oGT without blood glucose monitoring ( $\mathrm{aHR}=0.80,0.67,0.58,0.66$, respectively; $p<0.001$; Table 3 ). Furthermore, at the study endpoint, a significantly lower risk of mortality was observed in patients with FISHGw/GT with blood glucose monitoring than in patients with FISHGw/oGT without blood glucose monitoring (aHR $=0.71, p$ $<0.001$; Table 3).

\section{Discussion}

Using Taiwan's NHIRD, we found that FISHG patients without previous diabetes had a higher risk of stroke recurrence and mortality in both short and long terms than FISw/oHG. This study confirmed the short- and long-term prognostic effects of individual glycemic treatment on the decreased risk of mortality, but not of stroke recurrence, in patients with FISHG in the acute stroke phase. The risk of stroke recurrence within 1 year and mortality in both short and long terms were lower in patients with FISHG who received glycemic management (combined glycemic treatment with blood glucose monitoring) in the acute phase than those who did not receive glycemic management.

In this study, nondiabetic patients with FIS with hyperglycemia were $33.4 \%$, which is consistent with a systematic review, in which the prevalence of poststroke hyperglycemia ranged from $8-63 \%$ in nondiabetic patients with AIS 9, 17,25. Patients with FIS with hyperglycemia might present preexisting and unrecognized DM but mostly develop hyperglycemia as a stress reaction to brain damage ${ }^{9}$. Stress hyperglycemia after stroke was related to an increased risk of stroke recurrence and all-cause death at the 12-month follow-up in nondiabetic patients with AIS ${ }^{26}$. A direct association of poststroke hyperglycemia with increased risk of 
stroke recurrence and 3-month mortality was found in patients with ischemic stroke without previously diagnosed diabetes ${ }^{16}$. Patients with stroke with newly diagnosed DM based on glucose criteria (fasting plasma glucose $\geq 7.0 \mathrm{mmol} / \mathrm{L}$ or 2 -hour oral glucose tolerance test $\geq 11.1 \mathrm{mmol} / \mathrm{L}$ with/without $\mathrm{HbA} 1 \mathrm{c} \geq$ $6.5 \%$ ) were found to have a higher risk of stroke recurrence, poor functional outcomes, and mortality than nondiabetic patients at 1-year follow-up ${ }^{17}$. A study compared the functional outcomes, severity, and mortality of stroke at 3-month follow-up among patients with AIS with diagnosed DM, and the results indicated that patients with newly diagnosed DM after stroke had poorer functional outcome, severer strokes, and increased mortality compared with those with previously diagnosed $\mathrm{DM}^{25}$. In line with previous study results, this study's results indicated that patients with FISHG had a higher risk of stroke recurrence and mortality than those with FISw/oHG.

The mechanism underpinning the relation between poststroke hyperglycemia and poor prognoses of stroke is unclear. Poststroke hyperglycemia might be caused by neurohormonal dysfunction and the inflammatory response to ischemic brain damage ${ }^{27}$; furthermore, the complicated interaction of catecholamine, cortisol, and cytokine might induce an increase in the hepatic output of glucose ${ }^{28}$. Hyperglycemia exacerbates outcomes in patients with stroke through several possible pathophysiological mechanisms of neurotoxic effects, such as calcium imbalance, the accumulation of reactive oxygen species, increased lactic acidosis, decreased nitric oxide, and intensified inflammatory responses ${ }^{29}$. Insulin resistance and $\beta$-cell dysfunction cause relative insulin deficiency in hyperglycemia, which might increase the poor outcomes of nondiabetic patients with ischemic stroke ${ }^{30,31}$. These pathophysiological mechanisms may result in the enhancement of lipid peroxidation, free radical formation, and the accumulation of intracellular calcium; furthermore, cell lysis in the umbra and penumbra regions promote and accelerate ischemic injury ${ }^{15,32-34}$. A magnetic resonance imaging study reported that hyperglycemia is not only determined by the initial infarct volume but also by the infarct volume expansion ${ }^{35}$. Furthermore, prolonged poststroke hyperglycemia had been found to worsen neuronal damage and blood-brain dysfunction and increase the infarct volume growth in patients with ischemic stroke ${ }^{15,36}$.

In light of the adverse outcome in patients with poststroke hyperglycemia, guidelines recommend early glucose management for survival after stroke in patients with hyperglycemia ${ }^{2}$. Guidelines for the early management of AIS in patients with hyperglycemia recommend glycemic treatment to achieve blood glucose levels in a range of $140-180 \mathrm{mg} / \mathrm{dL}$ and the necessity of intensive blood glucose monitoring for preventing hypoglycemia, which can lead to further brain damage and poor outcomes ${ }^{2}$. Using insulin for glycemic treatment not only controlled blood glucose level but also had a neuroprotective effect through the augmentation of astrocytic glycogen phosphorylase ${ }^{34}$. Brain reperfusion after ischemic stroke might cause extensive reperfusion-induced glycogen accumulation in the ischemic penumbra and is strongly associated with the development of ischemia/reperfusion (I/R) injury, which leads to aggravating glutamate excitotoxicity, calcium overload, free radical formation, and inflammation ${ }^{37}$. In the past decade, growing evidence has been discovered in support of the proposition that insulin plays a crucial role in neuroprotection through the maintenance of calcium homeostasis, inhibition of inflammation, downregulation of free radical released in the heart, and modulation of glucose metabolism, which further prevent I/R injury ${ }^{38,39}$. Thus, glycemic treatment with insulin as a potential intervention for ischemic stroke focusing on glycogenolysis is 
promising. Nevertheless, the precise application of targeting strategies forglycemic treatment should be carefully considered depending on the timing of ischemia.

Although early glycemic management in acute stroke has a promising effect, previous studies have reported that intensive insulin therapy or glucose control in patients with acute stroke might not provide significant benefit in functional outcomes and survival and instead might cause hypoglycemic adverse effects ${ }^{19}$. This line of argument suggests that brain injury during the acute stroke phase increases the need for glucose and is vulnerable to glucose deficit ${ }^{40,41}$. Intensive glucose control within the normal range might lead to brain glycopenia, the metabolic crisis in the ischemic brain, and increased mortality ${ }^{42}$. Thus, glycemic treatment during acute stroke is controversial. Another challenge, namely a lack of hyperglycemia management in the acute stroke phase, is emerging and is worth noting.

The guidelines recommend blood glucose monitoring during glycemic treatment for the avoidance of iatrogenic hypoglycemia from insulin treatment and the maintenance of a safe glucose level of in patients with ischemic stroke ${ }^{2}$. The risk of stroke recurrence is the highest immediately after an ischemic stroke and gradually decreases and reaches a steady state by 6 months to 1 year after stroke onset ${ }^{43}, 44$. This study's results confirmed the benefit of glycemic treatment combined with blood glucose monitoring, particularly for the prevention of stroke recurrence within 1 year poststroke.

This study revealed that $>91 \%$ of FISHGw/GT patients had received blood glucose monitoring. Conversely, only $9 \%$ of the FISHGw/oGT cohort were prescribed blood glucose monitoring. A possible explanation is that the FISHGw/oGT cohort might present with a relatively stable blood glucose level in the acute phase, and blood glucose monitoring may be deemed unnecessary. The SHINE (Stroke Hyperglycemia Insulin Network Effort) multicenter randomized controlled trial proved that the optimal management of hyperglycemia at 80$130 \mathrm{mg} / \mathrm{dL}$ is safe and improves 3-month poststroke outcomes; however, researchers have emphasized the pivotal role of intensive and consistent blood glucose monitoring to avoid the onset of both hyperglycemia and hypoglycemia 45,46 . In line with SHINE study, our study data revealed that short- and long-term mortality are lower in FISHGw/GT with blood glucose monitoring than in FISHGw/oGT without blood glucose monitoring.

\section{Limitations of this Study}

This longitudinal cohort study has several limitations. First, the NIHRD data do not indicate whether hyperglycemia diagnoses after FIS were based on glucose or $\mathrm{HbA1c}{ }^{47}$, which might affect the prognostic value of stroke recurrence and mortality in this study. Second, we did not record stroke subtypes, which may be related to different clinical prognoses. Third, the detailed dose or the levels of glycemic treatment and blood glucose monitoring were beyond this study's scope. Therefore, we could not confirm the recommendation of the target levels of lower-glycemic treatment. Forth, mortality data retrieved from the NHIRD might not completely overlap with the death record in Taiwan, which might affect the validity thereof. However, the validity of death records in the NHIRD was tested through cross-comparison of the NHIRD data with death records from the catastrophic illness registry data files in a previous study, and the result indicated that its accuracy was high and valid ${ }^{48}$. 


\section{Conclusions}

Appropriate glycemic management, chiefly glycemic treatment accompanied by intensive blood glucose monitoring, may be dispensable for acute care of nondiabetic patients with FIS and hyperglycemia. This study did not explore the optimal glucose value at which corrective treatment should be initiated.

Nonetheless, this study provides general knowledge regarding the beneficial effects of glycemic management on stroke recurrence and mortality in patients with acute stroke through short- and long-term follow-ups. The risk of hyperglycemia in acute stroke is not arguable, but the optimal glycemic treatment and insulin benefit effect are still debatable. Therefore, the implementation of blood glucose monitoring is essential to achieve optimal glycemic management in the acute stroke phase and improving prognoses for patients with FISHG without previous diabetes.

\section{Declarations}

\section{Acknowledgements}

The authors thank the National Health Research Institute in Taiwan for providing the insurance claims data. This study was supported by a research grant (CMNDMC10806) from the Chi-Mei Medical Center in Taiwan.

\section{Author contributions}

H.H.Y. and Y.J.C. secured funding, conceptualized, designed, and performed the study, analyzed and interpreted the data, and wrote the manuscript. W.C.C., J.J.L., and C.C.Y. acquired, analyzed, and interpreted the data, review and edited the manuscript. C.H.C. and P.C.C acquired and analyzed the data.. T.T.L.advised on data collection and analysis, and edited the manuscript.

\section{Competing interests}

All authors declaire no competing interests.

\section{References}

1. Sacco, R. L. et al. An updated definition of stroke for the 21 st century: a statement for healthcare professionals from the American Heart Association/American Stroke Association., 44, 2064-2089 (2013).

2. Powers, W. J. et al. Guidelines for the Early Management of Patients With Acute Ischemic Stroke: 2019 Update to the 2018 Guidelines for the Early Management of Acute Ischemic Stroke: A Guideline for Healthcare Professionals From the American Heart Association/American Stroke Association. Stroke 50, e344-e418(2019).

3. Lin, B. et al. Cumulative risk of stroke recurrence over the last 10 years: a systematic review and metaanalysis. Neurol. Sci, 42, 61-71 (2021). 
4. Khanevski, A. N. et al. Recurrent ischemic stroke: Incidence, predictors, and impact on mortality. Acta. Neurol. Scand, 140, 3-8 (2019).

5. Jørgensen, H. S., Nakayama, H., Reith, J., Raaschou, H. O. \& Olsen, T. S. Stroke recurrence: predictors, severity, and prognosis. The Copenhagen Stroke Study. Neurology, 48, 891-895 (1997).

6. Marulaiah, S. K., Reddy, M. P., Basavegowda, M., Ramaswamy, P. \& Adarsh, L. S. Admission hyperglycemia an independent predictor of outcome in acute ischemic stroke: A longitudinal study from a tertiary care hospital in South India. Niger. J. Clin. Pract, 20, 573-580 (2017).

7. Muir, K. W., McCormick, M., Baird, T., Ali, M. \& Prevalence Predictors and Prognosis of Post-Stroke Hyperglycaemia in Acute Stroke Trials: Individual Patient Data Pooled Analysis from the Virtual International Stroke Trials Archive (VISTA). Cerebrovasc. Dis. Extra, 1, 17-27 (2011).

8. Marik, P. E. \& Bellomo, R. Stress hyperglycemia: an essential survival response!. Crit. Care, 17, 305 (2013).

9. Capes, S. E., Hunt, D., Malmberg, K., Pathak, P. \& Gerstein, H. C. Stress hyperglycemia and prognosis of stroke in nondiabetic and diabetic patients: a systematic overview., 32, 2426-2432 (2001).

10. Tziomalos, K. et al. Stress hyperglycemia and acute ischemic stroke in-hospital outcome. Metabolism, 67, 99-105 (2017).

11. Luitse, M. J., Biessels, G. J., Rutten, G. E., Kappelle, L. J. \& Diabetes hyperglycaemia, and acute ischaemic stroke. Lancet Neurol, 11, 261-271 (2012).

12. Sacco, R. L., Shi, T., Zamanillo, M. C. \& Kargman, D. E. Predictors of mortality and recurrence after hospitalized cerebral infarction in an urban community: the Northern Manhattan Stroke Study. Neurology, 44, 626-634 (1994).

13. Zhuo, Y. et al. Clinical risk factors associated with recurrence of ischemic stroke within two years: A cohort study., 99, e20830 (2020).

14. Nardi, K. et al. Predictive value of admission blood glucose level on short-term mortality in acute cerebral ischemia. J. Diabetes Complications 26, 70 - 6(2012).

15. Kes, V. B., Solter, V. V., Supanc, V. \& Demarin, V. Impact of hyperglycemia on ischemic stroke mortality in diabetic and non-diabetic patients. Ann. Saudi. Med, 27, 352-355 (2007).

16. Roquer, J. et al. Glycated Hemoglobin Value Combined with Initial Glucose Levels for Evaluating Mortality Risk in Patients with Ischemic Stroke. Cerebrovasc. Dis, 40, 244-250 (2015).

17. Jing, J. et al. Prognosis of Ischemic Stroke With Newly Diagnosed Diabetes Mellitus According to Hemoglobin A1c Criteria in Chinese Population., 47, 2038-2044 (2016).

18. Wan Sulaiman, W. A., Hashim, H. Z., Che Abdullah, S. T., Hoo, F. K. \& Basri, H. Managing post stroke hyperglycaemia: moderate glycaemic control is better? An update. EXCLI. J, 13, 825-833 (2014).

19. Fuentes, B. et al. European Stroke Organisation (ESO) guidelines on glycaemia management in acute stroke. Eur. Stroke. J, 3, 5-21 (2018).

20. Godoy, D. A., Behrouz, R. \& Di Napoli, M. Glucose control in acute brain injury: does it matter? Curr. Opin. Crit. Care, 22, 120-127 (2016).

21. Drury, P. et al. Management of fever, hyperglycemia, and swallowing dysfunction following hospital admission for acute stroke in New South Wales, Australia. Int. J. Stroke, 9, 23-31 (2014). 
22. Thomassen, L. et al. Acute stroke treatment in Europe: a questionnaire-based survey on behalf of the EFNS Task Force on acute neurological stroke care. Eur. J. Neurol, 10, 199-204 (2003).

23. Cheng, T. M., Taiwan's \& National Health Insurance System. : High Value for the Dollar. Six Countries, Six Reform Models: The Healthcare Reform Experience of Israel, The Netherlands, New Zealand, Singapore, Switzerland and Taiwan. p. 171-204 (2009).

24. Cheng, C. L., Kao, Y. H., Lin, S. J., Lee, C. H. \& Lai, M. L. Validation of the National Health Insurance Research Database with ischemic stroke cases in Taiwan. Pharmacoepidemiol. Drug Saf, 20, 236-242 (2011).

25. Mapoure, Y. N. et al. Acute Stroke Patients with Newly Diagnosed Diabetes Mellitus Have Poorer Outcomes than Those with Previously Diagnosed Diabetes Mellitus. J. Stroke Cerebrovasc. Dis, 27, 2327-2335 (2018).

26. Zhu, B. et al. Stress Hyperglycemia and Outcome of Non-diabetic Patients After Acute Ischemic Stroke. Front. Neurol, 10, 1003 (2019).

27. Dungan, K. M., Braithwaite, S. S. \& Preiser, J. C. Stress hyperglycaemia. Lancet 373, $1798-807(2009)$.

28. Roberts, G. W. et al. Relative Hyperglycemia, a Marker of Critical Illness: Introducing the Stress Hyperglycemia Ratio. J. Clinl. Endocrinol. Metab, 100, 4490-4497 (2015).

29. Li, W. A. et al. Hyperglycemia in stroke and possible treatments. Neurol. Res, 35, 479-491 (2013).

30. Pan, Y. et al. Pancreatic $\beta$-Cell Function and Prognosis of Nondiabetic Patients With Ischemic Stroke., 48, 2999-3005 (2017).

31. Jing, J. et al. Insulin Resistance and Prognosis of Nondiabetic Patients With Ischemic Stroke: The ACROSS-China Study (Abnormal Glucose Regulation in Patients With Acute Stroke Across China)., 48, 887-893 (2017).

32. Shin, T. H. et al. Metabolome Changes in Cerebral Ischemia. Cells9 (2020).

33. Chen, J. et al. High glucose induces apoptosis and suppresses proliferation of adult rat neural stem cells following in vitro ischemia. BMC Neurosci, 14, 24 (2013).

34. Cai, Y. et al. Glycogenolysis Is Crucial for Astrocytic Glycogen Accumulation and Brain Damage after Reperfusion in Ischemic Stroke. iScience 23, 101136(2020).

35. Parsons, M. W. et al. Acute hyperglycemia adversely affects stroke outcome: a magnetic resonance imaging and spectroscopy study. Ann. Neurol, 52, 20-28 (2002).

36. Shimoyama, T., Kimura, K., Uemura, J., Saji, N. \& Shibazaki, K. Elevated glucose level adversely affects infarct volume growth and neurological deterioration in non-diabetic stroke patients, but not diabetic stroke patients. Eur. J. Nneurol. 21, 402 - 10(2014).

37. Krewson, E. A. et al. The Proton-Sensing GPR4 Receptor Regulates Paracellular Gap Formation and Permeability of Vascular Endothelial Cells. iScience 23, 100848(2020).

38. Ashrafi, G., Wu, Z., Farrell, R. J. \& Ryan, T. A. GLUT4 Mobilization Supports Energetic Demands of Active Synapses. Neuron 93, $606-15 . e 3(2017)$.

39. Pearson-Leary, J., Jahagirdar, V., Sage, J. \& McNay, E. C. Insulin modulates hippocampally-mediated spatial working memory via glucose transporter-4. Behav. Brain Res, 338, 32-39 (2018). 
40. Bergsneider, M. et al. Cerebral hyperglycolysis following severe traumatic brain injury in humans: a positron emission tomography study. J. Neurosurg, 86, 241-251 (1997).

41. Carre, E. et al. Metabolic crisis in severely head-injured patients: is ischemia just the tip of the iceberg? Front. Neurol, 4, 146 (2013).

42. Kalfon, P. et al. Severe and multiple hypoglycemic episodes are associated with increased risk of death in ICU patients. Crit. Care, 19, 153 (2015).

43. Low molecular weight heparinoid. ORG 10172 (danaparoid), and outcome after acute ischemic stroke: a randomized controlled trial. The Publications Committee for the Trial of ORG 10172 in Acute Stroke Treatment (TOAST) Investigators. JAMA, 279, 1265-1272 (1998).

44. Wang, Y. et al. Association of hypertension with stroke recurrence depends on ischemic stroke subtype., 44, 1232-1237 (2013).

45. Gaillard, T. \& Miller, E. Guidelines for Stroke Survivors With Diabetes Mellitus., 49, e215-e7 (2018).

46. Bruno, A. et al. The Stroke Hyperglycemia Insulin Network Effort (SHINE) trial protocol: a randomized, blinded, efficacy trial of standard vs. intensive hyperglycemia management in acute stroke. Int. J. Stroke, 9, 246-251 (2014).

47. International Expert Committee. International Expert Committee report on the role of the A1C assay in the diagnosis of diabetes., 32, 1327-1334 (2009).

48. Cheng, C. L., Chien, H. C., Lee, C. H., Lin, S. J. \& Yang, Y. H. Validity of in-hospital mortality data among patients with acute myocardial infarction or stroke in National Health Insurance Research Database in Taiwan. Int. J. cardiol, 201, 96-101 (2015).

\section{Tables}

Table 1. Characteristics of study participants at baseline. FISw/oHG = FIS without hyperglycemia; FISHGw/oGT = FIS with hyperglycemia without glycemic treatment; FISHGw/GT = FIS with hyperglycemia with glycemic treatment. $p$ : chi-square/Fisher's exact test on category variables and one-way analysis of variance. 


\begin{tabular}{llllllllr} 
Group & Total & & \multicolumn{2}{l}{ FISw/oHG } & \multicolumn{2}{l}{ FISHGw/oGT } & \multicolumn{2}{l}{ FISHGw/GT } \\
\cline { 2 - 5 } & $\mathbf{n}$ & $\%$ & $\mathbf{n}$ & $\%$ & $\mathbf{n}$ & $\%$ & $\mathbf{n}$ & $\%$ \\
\hline Total & 207,054 & & 69,018 & & 69,018 & & 69,018
\end{tabular}

\section{Gender}

1.00

\begin{tabular}{llllllllll} 
Male & 121,029 & 58.45 & 40,343 & 58.45 & 40,343 & 58.45 & 40,343 & 58.45 & \\
\hline Female & 86,025 & 41.55 & 28,675 & 41.55 & 28,675 & 41.55 & 28,675 & 41.55 & \\
\hline Age (years) & $56.59 \pm 10.29$ & $56.60 \pm 10.33$ & $56.53 \pm 10.25$ & $56.63 \pm 10.31$ & 0.78 \\
\hline $\begin{array}{l}\text { Insured } \\
\text { premium } \\
\text { (NTS) }\end{array}$ & & & & & & & & & $<0.001$ \\
\end{tabular}

$\begin{array}{lllllllll}<18,000 & 64,422 & 31.11 & 21,875 & 31.69 & 21,472 & 31.11 & 21,075 & 30.54 \\ \begin{array}{l}18,000- \\ 34,999\end{array} & 121,211 & 58.54 & 40,210 & 58.26 & 40,567 & 58.78 & 40,434 & 58.58 \\ \geqq 35,000 & 21,421 & 10.35 & 6,933 & 10.05 & 6,979 & 10.11 & 7,509 & 10.88\end{array}$

Season

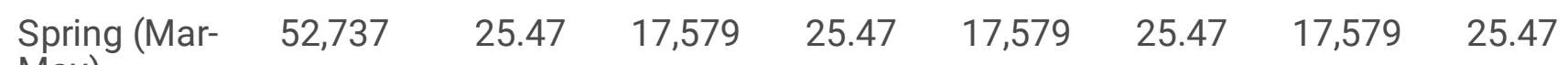
May)

\begin{tabular}{lccccccccc}
$\begin{array}{l}\text { Summer } \\
\text { (Jun-Aug) }\end{array}$ & 52,557 & 25.38 & 17,519 & 25.38 & 17,519 & 25.38 & 17,519 & 25.38 \\
\hline $\begin{array}{l}\text { Autumn } \\
\text { (Sep-Nov) }\end{array}$ & 50,988 & 24.63 & 16,996 & 24.63 & 16,996 & 24.63 & 16,996 & 24.63 & \\
$\begin{array}{l}\text { Winter (Dec- } \\
\text { Feb) }\end{array}$ & 50,772 & 24.52 & 16,924 & 24.52 & 16,924 & 24.52 & 16,924 & 24.52 & \\
\hline Location & & & & & & & & & $<0.001$ \\
\hline $\begin{array}{l}\text { Northern } \\
\text { Taiwan }\end{array}$ & 74,706 & 36.08 & 25,281 & 36.63 & 23,338 & 33.81 & 26,087 & 37.80 & \\
$\begin{array}{l}\text { Middle } \\
\text { Taiwan }\end{array}$ & 62,933 & 30.39 & 21,317 & 30.89 & 19,881 & 28.81 & 21,735 & 31.49 & \\
$\begin{array}{l}\text { Southern } \\
\text { Taiwan }\end{array}$ & 58,202 & 28.11 & 18,346 & 26.58 & 22,537 & 32.65 & 17,319 & 25.09 & \\
\hline $\begin{array}{l}\text { Eastern } \\
\text { Taiwan }\end{array}$ & 10,544 & 5.09 & 3,897 & 5.65 & 2,962 & 4.29 & 3,685 & 5.34 \\
$\begin{array}{l}\text { Outlets } \\
\text { islands }\end{array}$ & 669 & 0.32 & 177 & 0.26 & 300 & 0.43 & 192 & 0.28 \\
\hline
\end{tabular}

Urbanization level

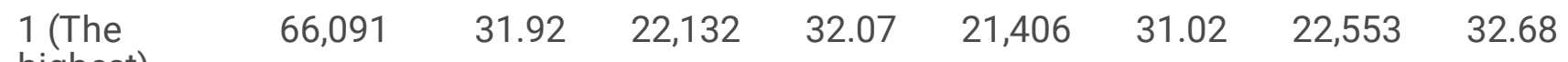
highest) 


\begin{tabular}{|c|c|c|c|c|c|c|c|c|c|}
\hline 2 & 89,934 & 43.44 & 30,270 & 43.86 & 28,297 & 41.00 & 31,367 & 45.45 & \\
\hline 3 & 14,565 & 7.03 & 4,586 & 6.64 & 5,593 & 8.10 & 4,386 & 6.35 & \\
\hline $\begin{array}{l}4 \text { (The } \\
\text { lowest) }\end{array}$ & 36,464 & 17.61 & 12,030 & 17.43 & 13,722 & 19.88 & 10,712 & 15.52 & \\
\hline Level of care & & & & & & & & & $<0.001$ \\
\hline $\begin{array}{l}\text { Hospital } \\
\text { center }\end{array}$ & 73,230 & 35.37 & 25,259 & 36.60 & 21,088 & 30.55 & 26,883 & 38.95 & \\
\hline $\begin{array}{l}\text { Regional } \\
\text { hospital }\end{array}$ & 95,349 & 46.05 & 30,641 & 44.40 & 33,644 & 48.75 & 31,064 & 45.01 & \\
\hline $\begin{array}{l}\text { Local } \\
\text { hospital }\end{array}$ & 38,475 & 18.58 & 13,118 & 19.01 & 14,286 & 20.70 & 11,071 & 16.04 & \\
\hline \multicolumn{10}{|l|}{$\begin{array}{l}\text { Blood } \\
\text { Glucose } \\
\text { Monitoring }\end{array}$} \\
\hline Yes & 69,885 & 50.63 & 0 & 0 & 6,213 & 9.00 & 63,672 & 92.25 & $<0.001$ \\
\hline No & 137.169 & 49.37 & 69,018 & 100 & 62,805 & 91.00 & 5,346 & 7.75 & \\
\hline
\end{tabular}

Table 2. Cox regression analysis for the risks of stroke recurrence and mortality of the FISw/oHG, FISHGw/oGT, and FISHGw/GT cohorts within 1 year and at the endpoint. The covariates of sex, age, monthly income, seasons, geographical area of residence, urbanization level of the residence, and levels of care were included in the multivariable model for adjustment; FISw/oHG = FIS without hyperglycemia; FISHGw/oGT = FIS with hyperglycemia without glycemic treatment; FISHGw/GT = FIS with hyperglycemia with glycemic treatment; $\mathrm{aHR}=$ adjusted hazard ratio, $\mathrm{Cl}=$ confidence interval; ${ }^{\dagger}=p<0.001$ as comparison of hazard ratio between FISHGw/oGT and FISHGw/GT cohorts; Endpoint = from the index date until death, withdrawal from the $\mathrm{NHI}$ program, or the end of 2015 , whichever occurred first. 


\begin{tabular}{|c|c|c|c|c|c|c|c|}
\hline \multirow[t]{2}{*}{ Follow-ups } & \multirow[t]{2}{*}{ Cohorts } & \multicolumn{3}{|c|}{ Stroke recurrence } & \multicolumn{3}{|c|}{ Mortality } \\
\hline & & AHR & $95 \% \mathrm{Cl}$ & $p$ & aHR & $95 \% \mathrm{Cl}$ & $p$ \\
\hline \multirow[t]{3}{*}{ 1-month } & FISW/oHG & & & & & & \\
\hline & FISHGw/oGT & 1.78 & $1.52-2.04$ & $<0.001$ & 1.54 & $1.19-1.89$ & $<0.001$ \\
\hline & FISHGw/GT & 1.41 & $1.18-1.65$ & $<0.001$ & 1.40 & $1.07-1.74$ & 0.001 \\
\hline \multirow[t]{3}{*}{ 3-month } & FISw/oHG & & & & & & \\
\hline & FISHGw/oGT & 1.35 & $1.04-1.65$ & 0.001 & 2.10 & $1.86-2.33$ & $<0.001$ \\
\hline & FISHGw/GT & 1.19 & $0.90-1.47$ & 0.12 & $1.43^{\dagger}$ & $1.23-1.63$ & $<0.001$ \\
\hline \multirow[t]{3}{*}{ 6-month } & FISw/oHG & & & & & & \\
\hline & FISHGw/oGT & 1.40 & $1.06-1.74$ & $<0.001$ & 1.83 & $1.54-2.12$ & $<0.001$ \\
\hline & FISHGw/GT & 1.34 & $1.03-1.65$ & 0.01 & $1.23^{\dagger}$ & $1.01-1.46$ & 0.02 \\
\hline \multirow[t]{3}{*}{ 1-year } & FISw/oHG & & & & & & \\
\hline & FISHGw/oGT & 1.37 & $1.19-1.64$ & $<0.001$ & 1.68 & $1.32-2.10$ & $<0.001$ \\
\hline & FISHGw/GT & 1.29 & $1.08-1.56$ & $<0.001$ & $1.35^{\dagger}$ & $1.07-1.68$ & $<0.001$ \\
\hline \multirow[t]{3}{*}{ Endpoint } & FISw/oHG & & & & & & \\
\hline & FISHGw/oGT & 1.35 & $1.31-1.39$ & $<0.001$ & 1.34 & $1.31-1.37$ & $<0.001$ \\
\hline & FISHGw/GT & 1.17 & $1.14-1.21$ & $<0.001$ & $1.11^{\dagger}$ & $1.08-1.14$ & $<0.001$ \\
\hline
\end{tabular}

Table 3. Short- and long-term prognostic effect of the glycemic treatment and blood glucose monitoring on stroke recurrence and mortality in FISHG patients. The covariates of sex, age, monthly income, season, geographical area of residence, urbanization level of the residence, and level of care were included in the multivariable model for adjustment; FISHG = FIS patients with hyperglycemia; FISHGw/oGT = FIS with hyperglycemia without glycemic treatment; FISHGw/GT = FIS with hyperglycemia with glycemic treatment; $\mathrm{BGM}=$ blood glucose monitoring; $\mathrm{aHR}=$ adjusted hazard ratio; $\mathrm{Cl}$ = confidence interval; Endpoint = from the index date until death, withdrawal from the $\mathrm{NHI}$ program, or the end of 2015 , whichever occurred first. 
Follow- Cohorts Stroke recurrence Mortality_ ups $\begin{array}{llllll}\text { AHR } & 95 \% \mathrm{Cl} & p & \text { aHR } & 95 \% \mathrm{Cl} & p\end{array}$

1-month FISHGw/oGT without BGM

FISHGw/OGT with BGM

$0.71 \quad 0.63$

0.79

FISHGw/GT without BGM

0.91

0.82

1.01

FISHGw/GT with BGM

$0.75 \quad 0.67-$

0.83

3-month

FISHGw/oGT without

BGM

FISHGw/oGT with BGM

0.724

$0.63-$

0.84

FISHGw/GT without BGM

$\begin{array}{ll}0.935 & 0.83- \\ & 1.03\end{array}$

$<0.001$

0.72

$0.67-0.77<0.001$

1.03

FISHGw/GT with BGM

$\begin{array}{ll}0.836 & 0.72- \\ 0.94\end{array}$

0.06

1.00

0.93-1.06

0.29

$<0.001$

0.80

$0.74-0.85<0.001$

FISHGW/GT with BGM

0.94

6-month

FISHGw/oGT without

BGM

FISHGw/OGT with BGM

0.92

$0.80-$

1.04

0.07

0.64

$0.53-0.79<0.001$

FISHGw/GT without BGM

0.95

0.82

1.09

FISHGw/GT with BGM

0.80

$0.69-$

0.91

1-year

FISHGw/oGT without
BGM

FISHGw/oGT with BGM

0.87

$0.72-$

0.95

FISHGw/GT without BGM

0.90

0.79

1.00

FISHGw/GT with BGM

0.82

$0.68-$

0.91

0.10

0.84

$0.74-0.93<0.001$

$\begin{array}{llll}<0.001 & 0.64 \quad 0.51-0.72 \quad<0.001\end{array}$

0.07

0.77

$0.68-0.88<0.001$ 


\section{Figures}

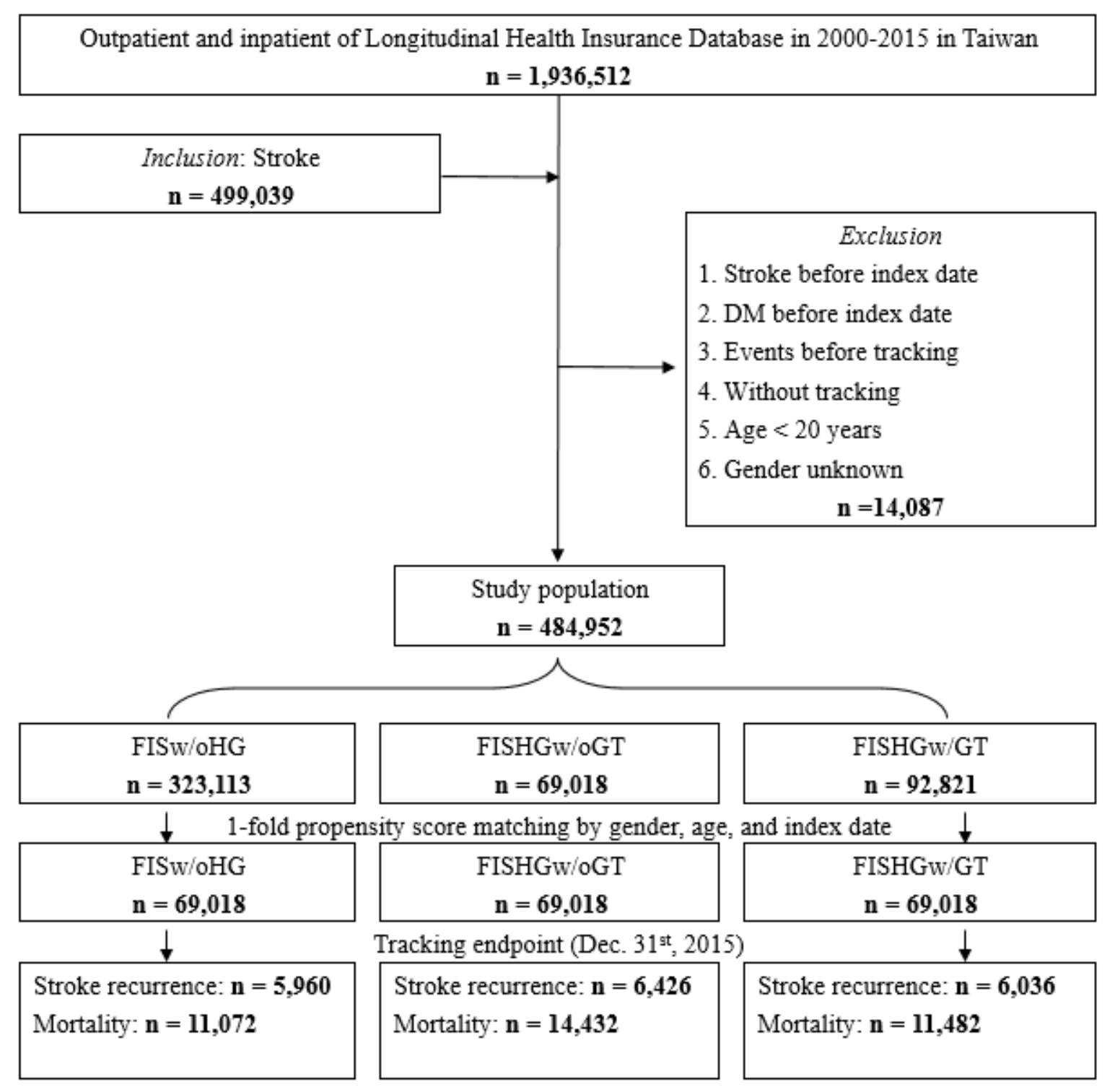

Figure 1

Flowchart of study sample selection from the National Health Insurance Research Database in Taiwan (matched). FISw/oHG = FIS without hyperglycemia; FISHGw/oGT = FIS with hyperglycemia without glycemic treatment; FISHGw/GT = FIS with hyperglycemia with glycemic treatment 
(a)
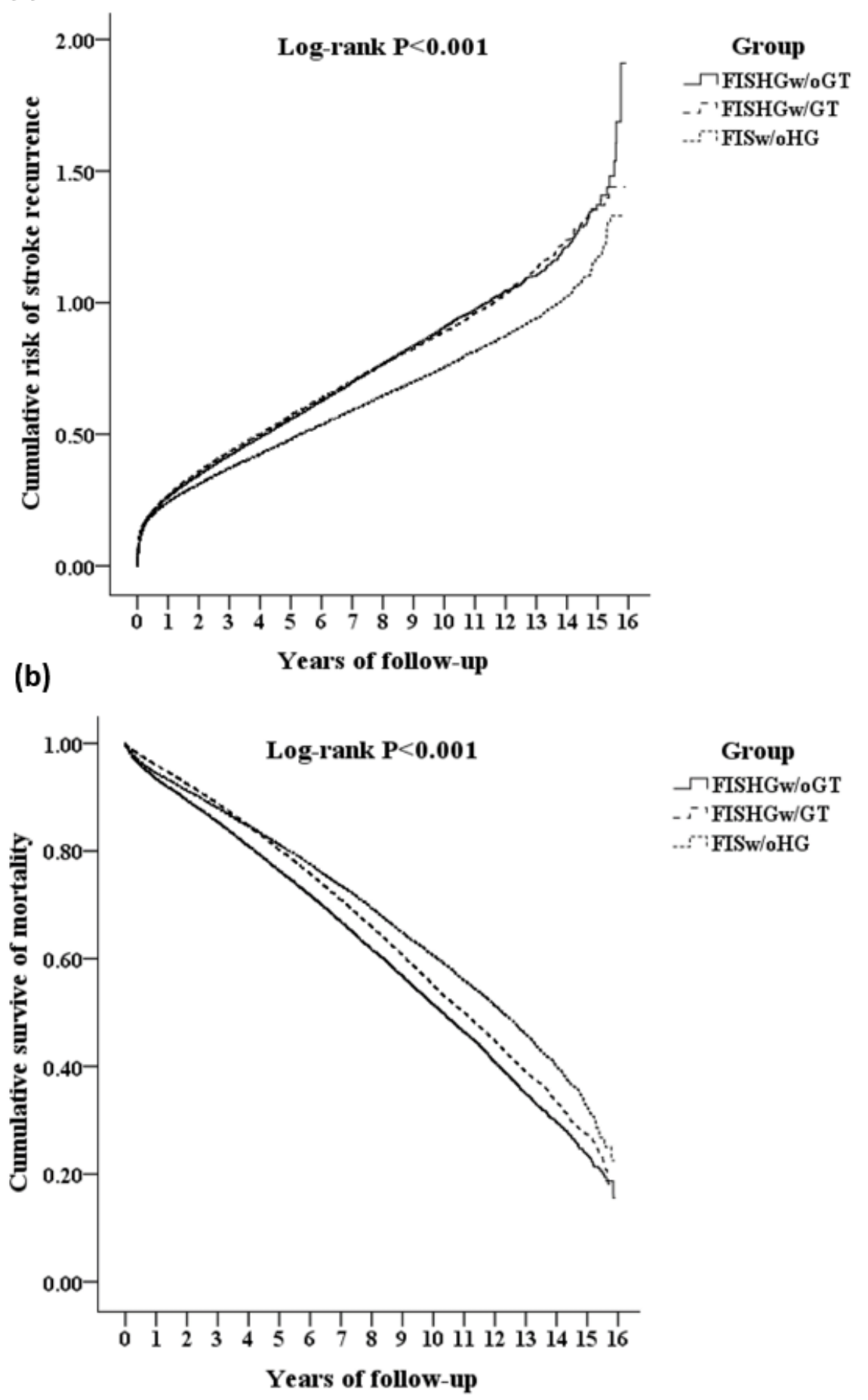

Figure 2

The Kaplan-Meier analysis comparing cumulative incidence of stroke recurrence (a) and mortality (b) among the FISw/oHG, FISHGw/oGT, and FISHGw/GT cohorts. FISw/oHG = FIS without hyperglycemia; FISHGw/oGT $=$ FIS with hyperglycemia without glycemic treatment; FISHGw/GT $=$ FIS with hyperglycemia with glycemic treatment. 